\title{
Effect of Water Chemistry on the Uptake of Co(II) on Graphene Oxide Investigated by Batch Technique
}

\author{
X. Tang*, J. Luo*, L. Wang** and X. Li*† \\ *College of Yuanpei, Shaoxing University, Shaoxing 312000, P. R. China \\ **College of Chemistry and Chemical Engineering, Shaoxing University, Shaoxing 312000, P. R. China \\ $†$ Corresponding authors: Xue Li; lixue@usx.edu.cn
}

Nat. Env. \& Poll. Tech.

Website: www.neptjournal.com

Received: 04-07-2020

Revised: 22-09-2020

Accepted: 09-10-2020

Key Words:

Co(II)

Graphene oxide

Isotherm

Water chemistry

\begin{abstract}
The uptake of $\mathrm{Co}(\mathrm{II})$ on graphene oxide (GO) by an adsorption process as a function of $\mathrm{pH}$ and ionic strength in the absence and presence of humic acid (HA) or fulvic acid (FA) was studied using batch technique. The results indicated that the uptake is strongly dependent on $\mathrm{pH}$ but independent of ionic strength. A stimulative effect of HA/FA on $\mathrm{Co}$ (II) uptake was found at $\mathrm{pH}<7.0$, whereas an inhibitory effect was observed at $\mathrm{pH}>7.0$. Kinetic studies suggest that $\mathrm{Co}$ (II) uptake on $\mathrm{GO}$ could be described more favorably by the pseudo-second-order kinetic model. The uptake isotherms can be described better by the Langmuir, Freundlich, and D-R models than by the linear model. The thermodynamic data calculated from the temperature-dependent uptake isotherms suggests that the uptake of Co(II) on GO is spontaneous and endothermic. Results of this work are of great importance for the environmental application of GO in the treatment of $\mathrm{Co}(\mathrm{II})$ from wastewater and indicated that $\mathrm{GO}$ is promising for the natural attenuation of $\mathrm{Co}(\mathrm{II})$ and related metal ions from aqueous solution.
\end{abstract}

\section{INTRODUCTION}

Pollution in the natural water due to hazardous and non-biodegradable heavy metal ions such as lead, cuprum, nickel, cadmium, and cobalt, originates from various human industrial activities such as electroplating, mining, fabrication of batteries, and microelectronics (Mobasherpour et al. 2014, Jin et al. 2015, Sun et al. 2015, Arancibia-Miranda et al. 2016, Sheng et al. 2016). It is a potential hazard to living systems; hence, it is essential to develop efficient and inexpensive materials and technologies to remove them from polluted water and recycle them. ${ }^{60} \mathrm{Co}(\mathrm{II})$ is one of the most serious radionuclides that encroach on the environment due to its long half-life $\left(\mathrm{T}_{1 / 2}=5.27 \mathrm{a}\right)$. The radionuclides ${ }^{60} \mathrm{Co}$ and ${ }^{58} \mathrm{Co}$ are present in liquid wastes released from pressurized water nuclear power reactors (Zhang et al. 2011). The permissible limits of cobalt in the irrigation water and livestock wastewaters are 0.05 and $1.0 \mathrm{mg} \cdot \mathrm{L}^{-1}$ respectively (Shibi et al. 2005). Cobalt poisoning in human beings may cause neuron toxicological disorders, genotoxicity, and cause cancer (Bhatnagar et al. 2010). Until now, various methods are in use to remove and recover heavy metals such as chemical precipitation (Chen et al. 2018), uptake (Ding et al. 2015), ion exchange (Komatsu et al. 2010), and membrane filtration (Almasian et al. 2018) among which uptake is considered an economical and effective strategy (Jin et al. 2014, Ma et al. 2015). Recently, numerous studies have investigated the uptake of $\mathrm{Co}(\mathrm{II})$ and related metal ions on a variety of adsorbents such as bentonite/iron oxide (Chen et al. 2011), alumina (Mou et al. 2012), $\mathrm{Fe}_{3} \mathrm{O}_{4} @$ cyclodextrin (Zhang et al. 2014), fungus/attapulgite composites (Cheng et al. 2015), and multiwalled carbon nanotubes/polyacrylamide composites (Yang et al. 2011). However, research seeking novel potential adsorbents for the removal of metal ions with much higher uptake capacities and efficiencies is always necessary.

Graphene (G), a single or several atomic layered graphites, is a fascinating new class of two-dimensional carbon nanostructures and possesses excellent mechanical, thermal, and electrical properties (Zhao et al. 2011, Deng et al. 2013, Luo et al. 2019). Graphene exhibits a huge surface area with a calculated value of $2630 \mathrm{~m}^{2} \cdot \mathrm{g}^{-1}$. It has shown great promise in the application of environmental pollution remediation. However, graphene itself is a hydrophobic substance, preventing it as an adsorbent for directly removing heavy metal ions from an aqueous solution. Graphene oxide (GO), the oxidation product of graphene containing epoxide, carbonyl, carboxyl, and hydroxyl functional groups, is hydrophilic, negatively charged, and readily disperses in an aqueous solution to form a stable suspension (Gao et al. 2011). Therefore, GO has the potential to remove heavy metal ions and organic pollutants in wastewater and has recently attracted significant attention as a high adsorbent in wastewater treatment (Bradder et al. 2011, Zhao et al. 2011). For instance, Wang 
et al. (2014) investigated the uptake of polycyclic aromatic hydrocarbons onto G and GO. Pei et al. (2013) used G and GO for the removal of 2-naphthol, 2,4,6-trichlorophenol, 1,2,4-trichlorobenzene, and naphthalene. Zhao et al. (2011) reported that GO showed a strong uptake capacity to $\mathrm{Pb}$ (II), $\mathrm{Cd}(\mathrm{II})$, and $\mathrm{Co}(\mathrm{II})$. Besides, they found that the uptake of heavy metal ions is dependent on the extent of O-containing functional groups. Ramesha et al. (2011) studied the uptake of anionic and cationic dyes on G and GO. They also studied the uptake of $\mathrm{Cu}$ (II) and $\mathrm{Ni}(\mathrm{II})$ on $\mathrm{GO}$ as a function of solution chemistry (Li et al. 2014, 2015). All these investigations indicated $\mathrm{G}$ and GO showed an outstanding capability in the removal of a wide range of organic and inorganic contaminants. Nevertheless, to our knowledge, there is little information about the simultaneous uptake of metal ions and organics on GO. And we should realize that metal ions and organics may exist simultaneously in the real environment. For example, the presence of soil humic substances like humic acid (HA) or fulvic acid (FA) obviously influences the uptake of metal ions at the interface (Sheng et al. 2014a, b). So, it is very necessary to study the uptake of metal ions on $\mathrm{GO}$ in the presence of organic contaminants and vice versa.

Hence, to extend the practical application of GO in metal ion remediation, $\mathrm{Co}(\mathrm{II})$ as a chemical analog of radionuclides was selected in this paper. The objectives of this paper were: (1) to study the uptake kinetics and to simulate the data with a pseudo-second-order equation; (2) to investigate the effect of water chemistries (e.g., reaction time, $\mathrm{pH}$, ionic strength, and temperature) on $\mathrm{Co}$ (II) onto GO by batch techniques; (3) to determine the uptake mechanism between $\mathrm{Co}$ (II) and GO; (4) The regeneration and reuse of GO in Co(II) uptake were also studied. The highlight of this paper is that the potential application of GO towards the removal of radionuclides from aqueous solutions in environmental remediation strategy.

\section{MATERIALS AND METHODS}

\section{Materials and Reagents}

GO was prepared using the modified Hummers method; the results of the SEM and TEM characterization of the prepared GO are shown in Fig. 1. From the SEM images (Fig. 1A) we can see that the GO was randomly accumulated by thin nanosheets in a loose state, the surface is smooth, and there was a crimp in the fold oxidation state. More finely, as shown in the TEM image (Fig. 1B), the GO film is transparent and typically wrinkled, sheet-like structures. All reagents used in the experiments were purchased in analytical purity and used without any purification. All solutions were prepared with Milli-Q water. Add $0.8075 \mathrm{~g} \mathrm{CoCl}_{2} \cdot 6 \mathrm{H}_{2} \mathrm{O}$ analytical reagent into a beaker, add an appropriate amount of deionized water to dissolve, and then pour it into a $1000 \mathrm{~mL}$ volumetric flask. Add deionized water to the volumetric flask to the scale line to obtain the $\mathrm{Co}$ (II) stock solution in a concentration of 200 $\mathrm{mg} \cdot \mathrm{L}^{-1}$. The prepared Co(II) stock solution was diluted to the required concentrations in the following experiments. The humic acid (HA) and fulvic acid (FA), which were obtained as a gift from the Institute of Plasma Physics, Chinese Academy of Sciences, were extracted from the soil of Hua-Jia county (Gansu province, China) and had been characterized in detail previously (Tan et al. 2009).

\section{Uptake Procedures}

The uptake of Co(II) on GO was investigated by using the batch technique in polyethylene centrifuge tubes under dif-
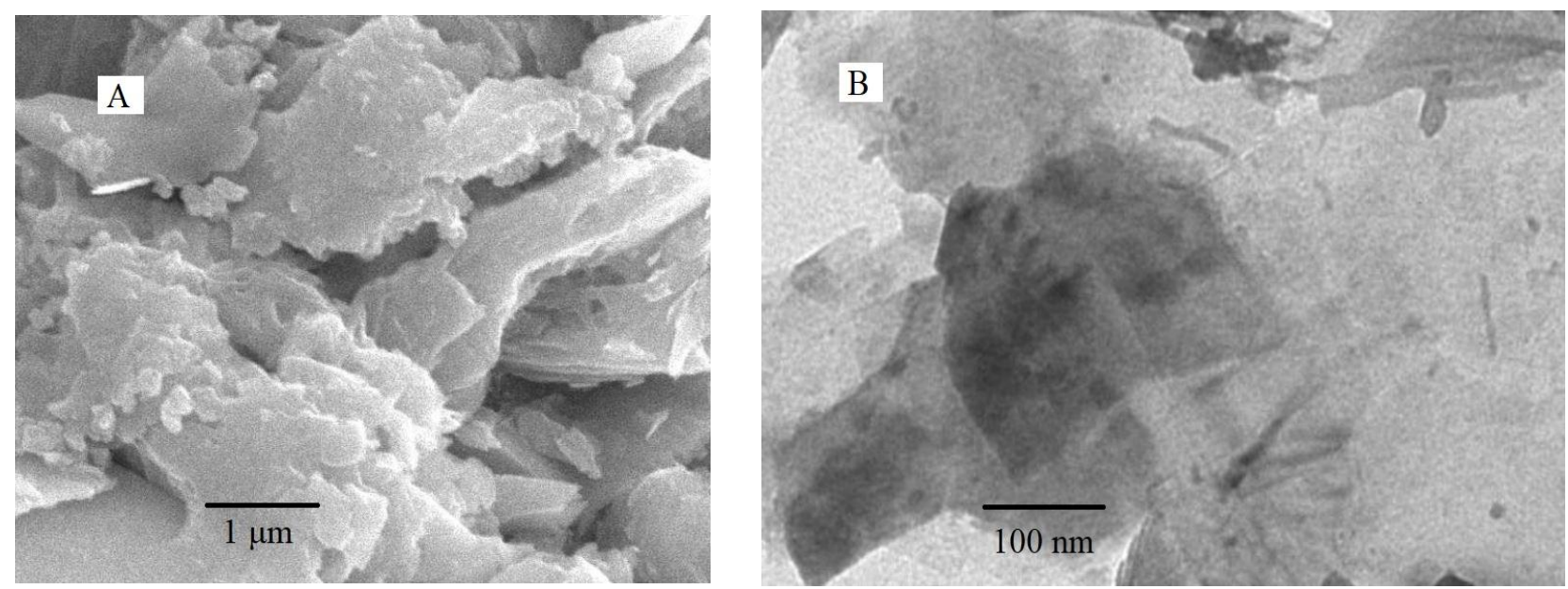

Fig. 1: (A) SEM and (B) TEM of GO. 
ferent chemical conditions. The stock suspension of GO and $\mathrm{NaNO}_{3}$ solution was first contacted for two days to achieve the equilibration of $\mathrm{GO}$ and $\mathrm{NaNO}_{3}$. Then, $\mathrm{Co}$ (II) stock solution and FA or HA stock solution were added to achieve the desired concentrations of different components. The system was adjusted to the desired $\mathrm{pH}$ by adding inappreciable volumes of $0.01 \mathrm{~mol} \cdot \mathrm{L}^{-1} \mathrm{HNO}_{3}$ or $\mathrm{NaOH}$. After the suspensions were shaken for two days, the solid and liquid phases were separated by centrifugation at $9000 \mathrm{rpm}$ for $60 \mathrm{~min}$ at the same temperature control to the uptake experiments. The concentration of ${ }^{60} \mathrm{Co}$ (II) was analyzed by liquid scintillation counting using a Packard 3100 TR/AB Liquid Scintillation Analyzer (PerkinElmer). The scintillation cocktail was ULTIMA GOLD AB ${ }^{\mathrm{TM}}$ (Packard) (Chen et al. 2011). The amount of $\mathrm{Co}$ (II) absorbed on $\mathrm{GO}$ was calculated from the difference between the initial concentration and the equilibrium one.

For reversibility and regeneration study, a typical treatment process was conducted by adding $500 \mathrm{~mL}$ of 0.01 $\mathrm{mol} \cdot \mathrm{L}^{-1} \mathrm{NaNO}_{3}$ and $10 \mathrm{mg} \cdot \mathrm{L}^{-1} \mathrm{Co}(\mathrm{II})$ into a $1 \mathrm{~L}$ beakers containing $\mathrm{GO}$ with three different concentrations (i.e., 0.05, 0.1 , and $0.2 \mathrm{~g} \cdot \mathrm{L}^{-1}$ ). The $\mathrm{pH}$ was adjusted to a certain value. The suspensions were continuously stirred for $24 \mathrm{~h}$ by using a mechanical mixer and then separated, and the obtained supernatants were used for the measurement of $\mathrm{Co}$ (II) concentration. The solid was washed with $0.001 \mathrm{~mol} \cdot \mathrm{L}^{-1} \mathrm{HNO}_{3}$ and high-purity Milli-Q water, until Co(II) could be determined, collected, and dried at $60{ }^{\circ} \mathrm{C}$. The recovered GO was used for $\mathrm{Co}(\mathrm{II})$ uptake a second time. According to this process, the adsorption-desorption process was repeated 6 times.

The uptake of $\mathrm{Co}$ (II) was expressed in terms of distribution coefficient $\left(\mathrm{K}_{\mathrm{d}}\right)$ and uptake percentage $(\%)$ was derived from the following equations (Zhang et al. 2014):

$$
\begin{gathered}
K_{d}=\frac{C_{0}-C_{e}}{C_{e}} \frac{V}{m} \\
\text { uptakepercentage }(\%)=\frac{C_{0}-C_{e}}{C_{0}} \times 100 \%
\end{gathered}
$$

where $\mathrm{C}_{0}$ is the initial concentration, $\mathrm{C}_{\mathrm{e}}$ is the concentration in supernatant after centrifugation, $\mathrm{m}$ is the mass of $\mathrm{GO}$, and $\mathrm{V}$ is the volume of the suspension.

\section{RESULTS AND DISCUSSION}

\section{Impact of Contact Time}

To establish the equilibration time for maximum uptake and the uptake capacity of different solid content, and to know the kinetics of the uptake process, $\mathrm{Co}$ (II) uptake on the GO of three different concentrations (i.e., 0.05, 0.1, and $0.2 \mathrm{~g} \cdot \mathrm{L}^{-1}$ ) were investigated as a function of contact time and the results are shown in Fig. 2. It can be seen from Fig. 2A that Co(II) uptake on GO increases rapidly at the initial contact time of $1.5 \mathrm{~h}$, and then increases slowly in the following contact time. Specifically, the equilibrium uptake amount decreases from 104.13 to $36.43 \mathrm{mg} \cdot \mathrm{g}^{-1}$ with the GO concentration increasing from 0.05 to $0.2 \mathrm{~g} \cdot \mathrm{L}^{-1}$. This result indicates that $\mathrm{Co}$ (II) uptake on GO is attributed to chemical interaction rather than physical interaction.

To help deduce the uptake mechanisms, the experimental kinetic data of $\mathrm{Co}$ (II) on GO are simulated by using the pseudo-second-order models (Zhang et al. 2014):

$$
\frac{t}{q_{t}}=\frac{1}{2 k q_{e}^{2}}+\frac{t}{q_{e}}
$$

In the equations, $\mathrm{q}_{\mathrm{t}}\left(\mathrm{mg} \cdot \mathrm{g}^{-1}\right)$ is the amount of $\mathrm{Co}(\mathrm{II})$ uptake on $\mathrm{GO}$ at time $\mathrm{t}(\mathrm{h}), \mathrm{q}_{\mathrm{e}}\left(\mathrm{mg} \cdot \mathrm{g}^{-1}\right)$ is the equilibrium $\mathrm{Co}(\mathrm{II})$ capacity, and $\mathrm{k}\left(\mathrm{g} \cdot \mathrm{mg}^{-1} \cdot \mathrm{h}^{-1}\right)$ is the rate constant of an uptake process. The straight-line plots of $t / q_{t}$ versus $t$ (Fig. 2B) indicate that the kinetic uptake of $\mathrm{Co}$ (II) on GO is well described by the pseudo-second-order rate equation. The values of $\mathrm{k}$ and $\mathrm{q}_{\mathrm{e}}$ determined from the slopes and intercepts of the kinetic model are listed in Table 1. The correlation coefficients of the pseudo-second-order rate equation for the linear plot are very close to 1 , which suggests that the kinetic uptake can be described by the pseudo-second-order rate equation very well.

\section{Effect of Solid Content}

Fig. 3 shows the dependence of $\mathrm{Co}(\mathrm{II})$ uptake on $\mathrm{GO}$ as a function of solid content at $\mathrm{T}=293 \mathrm{~K}$ and $\mathrm{pH}=6.0 \pm 0.1$. As can be seen that the uptake percentage of $\mathrm{Co}$ (II) increases rapidly with increasing GO contents. With increasing solid contents, the number of functional groups at the GO surfaces increases, hence, more exchangeable surface sites are available to form complexes with $\mathrm{Co}$ (II) at solid surfaces. As can be seen from Fig. 3, the uptake capacity of Co(II) on GO decreases gradually with the increase of solid content. These phenomena can be attributed to three reasons: (1) The solid surface is composed of sites with a spectrum of binding energies. At low GO content, all kinds of surface sites are entirely exposed for uptake $\mathrm{Co}(\mathrm{II})$ and the surface gets to saturation faster, resulting in a higher uptake capacity. But at higher particle concentrations, the availability of higher energy sites decreases with a larger fraction of lower energy sites becoming occupied, leading to a lower uptake capacity (Huang et al. 2008); (2) The higher GO amount enhances the probability of collision between GO particles and therefore creates particle aggregation, causing a decrease in the total surface area and an increase in diffusion path length, both of which contribute to the decrease in the uptake capacity of $\mathrm{Co}(\mathrm{II})$ on $\mathrm{GO}$ (Li et al. 2011); (3) The increase ratio of 

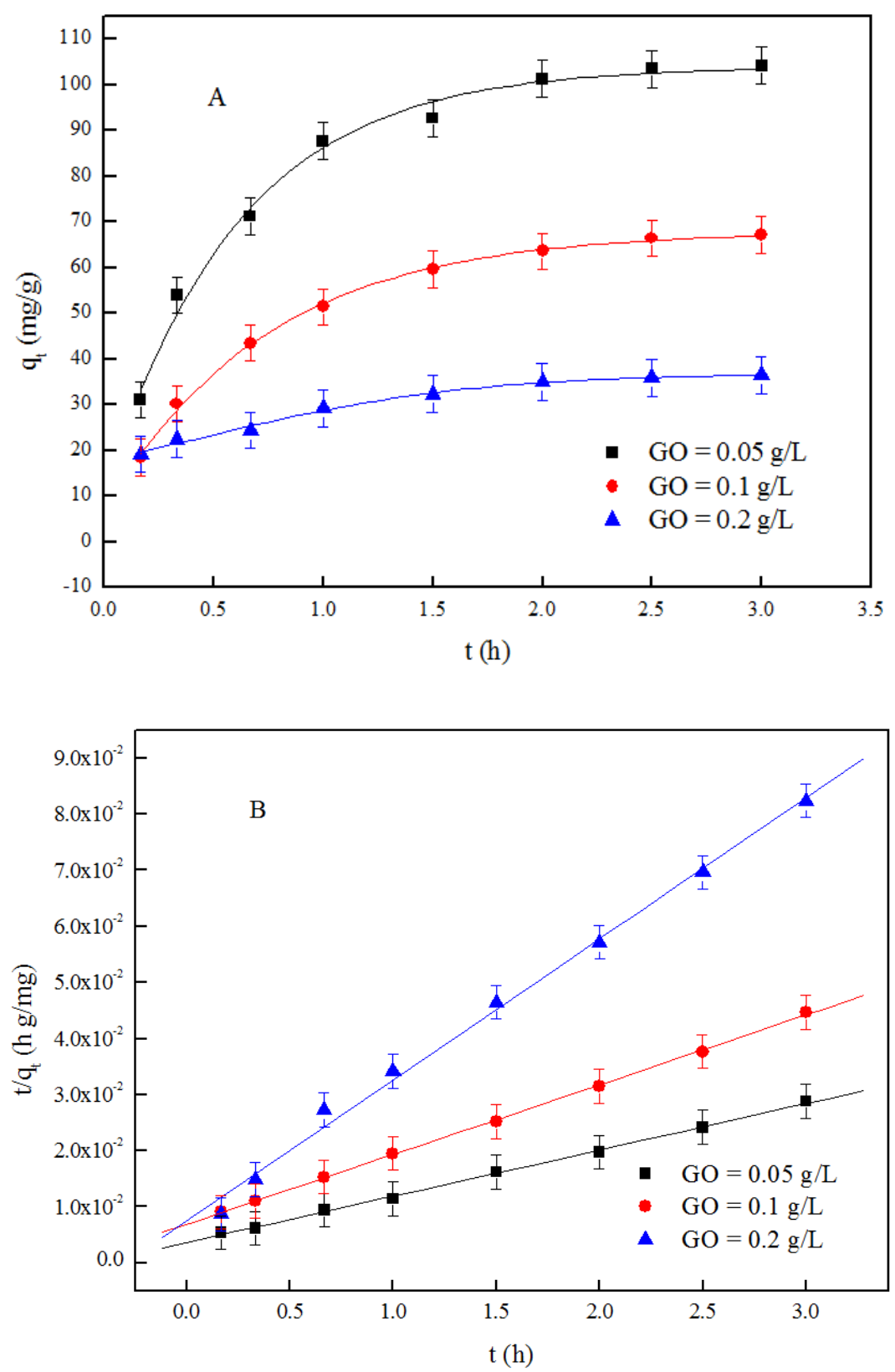

Fig. 2: (A) Uptake of Co(II) on GO as a function of contact time, (B) Plot of $t / q_{t}$ vs. $t$ for the Pseudo-second-order rate calculation of Co(II) uptake on $\mathrm{GO}, \mathrm{T}=293 \mathrm{~K}, \mathrm{pH}=6.0 \pm 0.1, \mathrm{C}_{\mathrm{Co}(\mathrm{II}) \text { initial }}=10 \mathrm{mg} / \mathrm{L}, \mathrm{I}=0.1 \mathrm{~mol} / \mathrm{L} \mathrm{NaNO}_{3}$.

Table 1: Kinetic parameters of Co(II) uptake on GO.

\begin{tabular}{|llll|}
\hline \multirow{2}{*}{$\begin{array}{l}\text { GO } \\
\text { g/L })\end{array}$} & \multicolumn{3}{c|}{ Pseudo-second-order parameters } \\
\cline { 2 - 4 } & $\mathrm{q}_{\mathrm{e}}\left(\mathrm{mg} \cdot \mathrm{g}^{-1}\right)$ & $\mathrm{k}\left(\mathrm{g} \cdot \mathrm{mg}^{-1} \cdot \mathrm{h}^{-1}\right)$ & $\mathrm{R}^{2}$ \\
\hline 0.05 & 120.9190 & 0.0095 & 0.9984 \\
0.1 & 80.5153 & 0.0112 & 0.9995 \\
0.2 & 39.7614 & 0.0423 & 0.9949 \\
\hline
\end{tabular}


net uptake quantity of $\mathrm{Co}$ (II) on GO surface is lower than that of the solid content, correspondingly decreasing the uptake capacity of $\mathrm{Co}(\mathrm{II})$ on GO. This result implies that the augmentation of GO could not unboundedly increase the contact area between metal ions and the solid surface. At the same time, the competition uptake between the sorbent will also reduce the uptake ability of solid particles. Thus, with a view to reducing the cost of pollution treatment in actual application, one should choose a suitable sorbent dosage according to the pollutant concentrations and required removal efficiency.

\section{Impact of pH and Ionic Strength}

The $\mathrm{pH}$ dependence of $\mathrm{Co}(\mathrm{II})$ uptake on $\mathrm{GO}$ ranging from 2.0 to 10.0 at three different ionic strengths (i.e., $0.001,0.01$, and $0.1 \mathrm{~mol} \cdot \mathrm{L}^{-1} \mathrm{NaNO}_{3}$ ) is shown in Fig. 4 . As can be seen, the $\mathrm{pH}$ values of the aqueous solution play an important role in the uptake of $\mathrm{Co}$ (II) on GO. With the $\mathrm{C}_{\mathrm{CO}(\mathrm{II}) \text { initial }}$ of 10 $\mathrm{mg} \cdot \mathrm{L}^{-1}$, the uptake of $\mathrm{Co}(\mathrm{II})$ on GO increases slowly with $\mathrm{pH}$ ranging from 2.0 to 4.0 , then increases abruptly with $\mathrm{pH}$ 4.0-8.0 and at last maintains the high uptake level with $\mathrm{pH}$ increasing at $\mathrm{pH}>8.0$. About $90 \%$ of $\mathrm{Co}$ (II) is absorbed on $\mathrm{GO}$ at $\mathrm{pH}>8.0$.

The uptake of metal ions on sorbents is obviously affected by $\mathrm{pH}$ values because it not only influences metal ion species in solution but also affects the surface properties of the sorbents according to dissociation of functional groups and surface charge. The increase of $\mathrm{Co}$ (II) uptake on GO with increasing solution $\mathrm{pH}$ may be attributed to the surface properties of GO in terms of surface charge and dissociation of functional groups. Because of the protonation reaction (i.e., $\mathrm{MOH}+\mathrm{H}^{+} \Leftrightarrow \mathrm{MOH}_{2}^{+}$), the GO surface contains a large number of binding sites and can become positively charged at low $\mathrm{pH}$. The electrostatic repulsion occurred between $\mathrm{Co}$ (II) and the positively charged sites $\left(\mathrm{MOH}_{2}^{+}\right)$on $\mathrm{GO}$ results in the low uptake of $\mathrm{Co}(\mathrm{II})$. At high $\mathrm{pH}$, the GO surface becomes negatively charged due to the deprotonation process (i.e., $\mathrm{MOH} \Leftrightarrow M \mathrm{O}^{-}+\mathrm{H}^{+}$) and electrostatic repulsion obviously decreases with $\mathrm{pH}$ raising, which enhances the uptake of $\mathrm{Co}$ (II) on GO through electrostatic force of attraction (Yang et al. 2011, Deng et al. 2013). At the same time, another factor needs to be considered, that is, the increase in $\mathrm{pH}$ values may lead to $\mathrm{Co}$ (II) precipitation on the GO surface. Previous research has reported that the hydrolysis is constant of $\mathrm{Co}(\mathrm{OH})_{2}$ is $1.58 \times 10^{-14.80}$ (Chen et al. 2011). In our study, the initial concentration of $\mathrm{Co}$ (II) is $10 \mathrm{mg} \cdot \mathrm{L}^{-1}$, so $\mathrm{Co}(\mathrm{II})$ begins to form precipitation at a $\mathrm{pH}$ of about 8.7. However, at $\mathrm{pH} 8.0$, the $\mathrm{Co}(\mathrm{II})$ ions are absorbed on GO completely. Consequently, it is impossible to form precipitation because of the very low concentration of $\mathrm{Co}$ (II) that remained in the solution. Hence, the sharp increase of Co(II) uptake on GO at $\mathrm{pH} 4.0-8.0$ is not attributed to the $\mathrm{Co}(\mathrm{II})$ precipitation.

Fig. 4 also displays the impact of ionic strength on Co(II) uptake on GO. We can see that ionic strength showed a negligible effect on Co(II) uptake. The uptake is weakly affected by ionic strength at $\mathrm{pH} 4-8$ and no effect is approximately

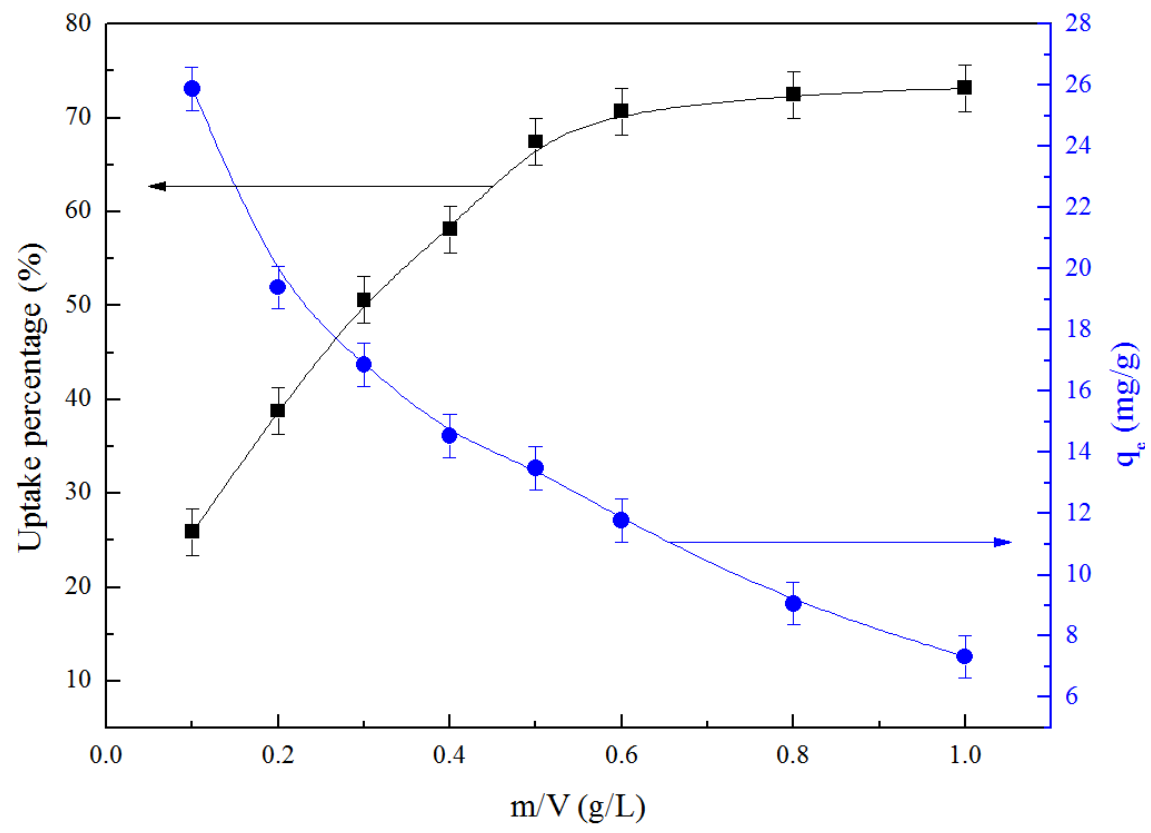

Fig. 3: Uptake of $\mathrm{Co}(\mathrm{II})$ on $\mathrm{GO}$ as a function of solid content at $\mathrm{T}=293 \mathrm{~K}, \mathrm{pH}=6.0 \pm 0.1, \mathrm{C}_{\mathrm{Co}(\mathrm{II}) \text { initial }}=10 \mathrm{mg} / \mathrm{L}, \mathrm{I}=0.1 \mathrm{~mol} / \mathrm{L} \mathrm{NaNO}$. 
found at $\mathrm{pH}<4.0$ or $\mathrm{pH}>8.0$. The ionic strength may affect the double electrode layer thickness and interface potential, hence, affecting the binding of the adsorbed species. Outer-sphere surface complexes are regarded to be more impressionable to ionic strength variations than inner-sphere complexes as the background electrolyte ions are placed in the same plane for outer-sphere surface complexes (Hayes \& Leckie 1987). Based on this theory and the results of these studies, we can deduce that inner-sphere surface complexation is the main mechanism of Co(II) uptake on GO.

\section{Impact of Humic Substances}

The humic acid (HA) and fulvic acid (FA), which are ubiquitous in the natural environment, can influence the uptake and transport of metal ions significantly as both of them can form strong complexes with metal ions (Sheng et al. 2014a, b). The uptake of $\mathrm{Co}$ (II) on GO in the presence/absence of FA/HA under different $\mathrm{pH}$ values is shown in Fig. 5. We can see that the presence of FA or HA enhances the uptake of $\mathrm{Co}$ (II) on $\mathrm{GO}$ at $\mathrm{pH}<7.0$, while $\mathrm{Co}$ (II) uptake was restrained at high $\mathrm{pH}>$ 7.0. The uptake of HA and FA onto GO as a function of $\mathrm{pH}$ was determined in previous work ( $\mathrm{Li}$ et al. 2014), and it was found that $90 \%$ of HA/FA can be absorbed on GO at low $\mathrm{pH}$, and then the uptake decreases with $\mathrm{pH}$ increasing. It was reported that both HA and FA were negatively charged at pH 3.0-10.0 (Sheng et al. 2012). Hence, at low pH, the negatively-charged HA/FA can be easily absorbed onto the positively-charged GO surface as a result of electrostatic attraction, resulting in the enhancement of $\mathrm{Co}(\mathrm{II})$ uptake onto GO due to the strong complexation ability of surface absorbed HA/FA with $\mathrm{Co}$ (II). However, at high $\mathrm{pH}$, it is very difficult for the negatively-charged HA/FA to be adsorbed onto the negatively-charged GO surface due to the electrostatic repulsion, therefore, the HA/FA in solution forms HA/FA-Co(II) soluble complexes, and thereby the uptake of $\mathrm{Co}$ (II) onto GO was greatly reduced. Similar results found the presence of HA/FA imposing a positive role in Ni(II) adsorption onto $\mathrm{GO}$ at low $\mathrm{pH}$, whereas a negative role in the adsorption of $\mathrm{Ni}(\mathrm{II})$ onto $\mathrm{GO}$ was observed at high $\mathrm{pH}$ in previous work ( $\mathrm{Li}$ et al. 2015).

\section{Uptake Isotherms of Co(II) on GO and Thermodynamic Study}

The uptake isotherms for $\mathrm{Co}$ (II) on GO at 293, 313, and $333 \mathrm{~K}$ are shown in Fig. 6. It is clear from Fig. 6 that the uptake isotherm is the highest at $\mathrm{T}=333 \mathrm{~K}$ and is the lowest at $\mathrm{T}=293 \mathrm{~K}$. The result indicates that high temperature is advantageous for $\mathrm{Co}$ (II) uptake on GO. This phenomenon may be attributed to two key factors (Hu et al. 2010, Jin et al. 2014): (1) Increased diffusion rate of Co(II) into GO surface binding sites due to increased temperature that contributes to the observed uptake; (2) The increase in reaction temperature may increase in proportion and activity of $\mathrm{Co}(\mathrm{II})$ ions in solution, the affinity of $\mathrm{Co}$ (II) ions to GO surface, or the charge and the potential of GO surface. Four different models, viz. Linear, Langmuir, Freundlich, and D-R isotherm equations

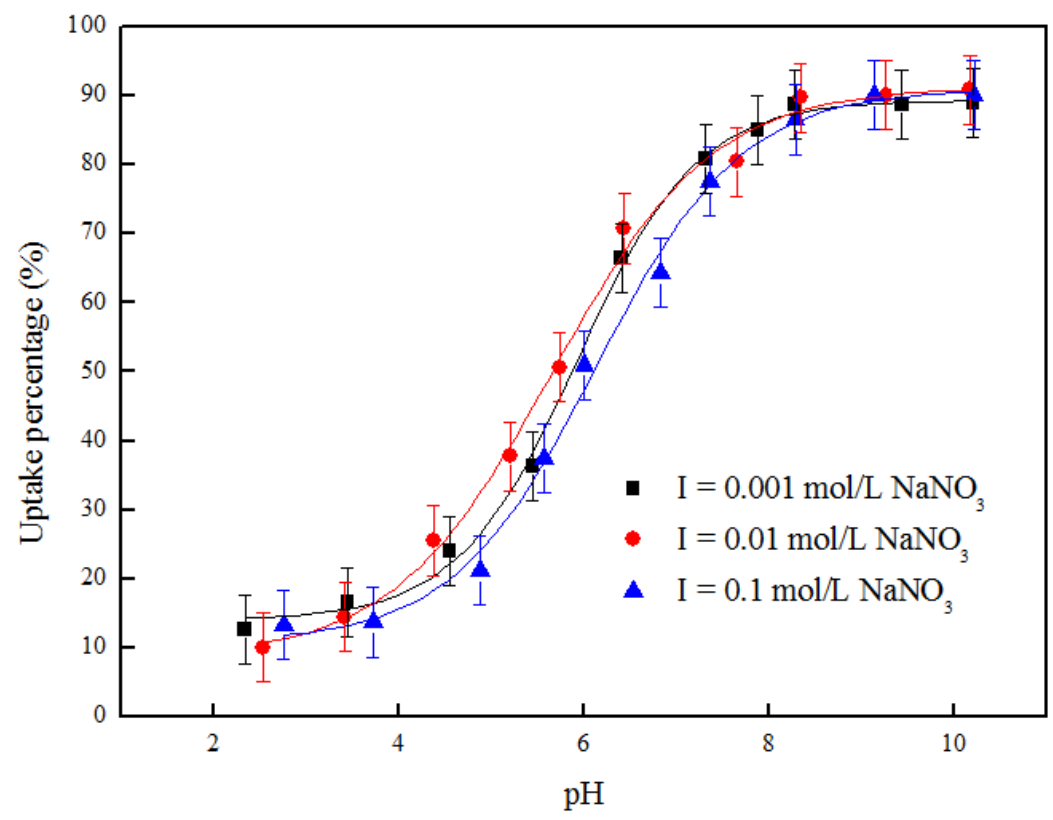

Fig. 4: The role of $\mathrm{pH}$ and ionic strength in Co(II) uptake on $\mathrm{GO}, \mathrm{T}=293 \mathrm{~K}, \mathrm{C}_{\mathrm{Co}(\mathrm{II}) \text { initial }}=10 \mathrm{mg} / \mathrm{L}, \mathrm{m} / \mathrm{V}=0.1 \mathrm{~g} / \mathrm{L}$. 


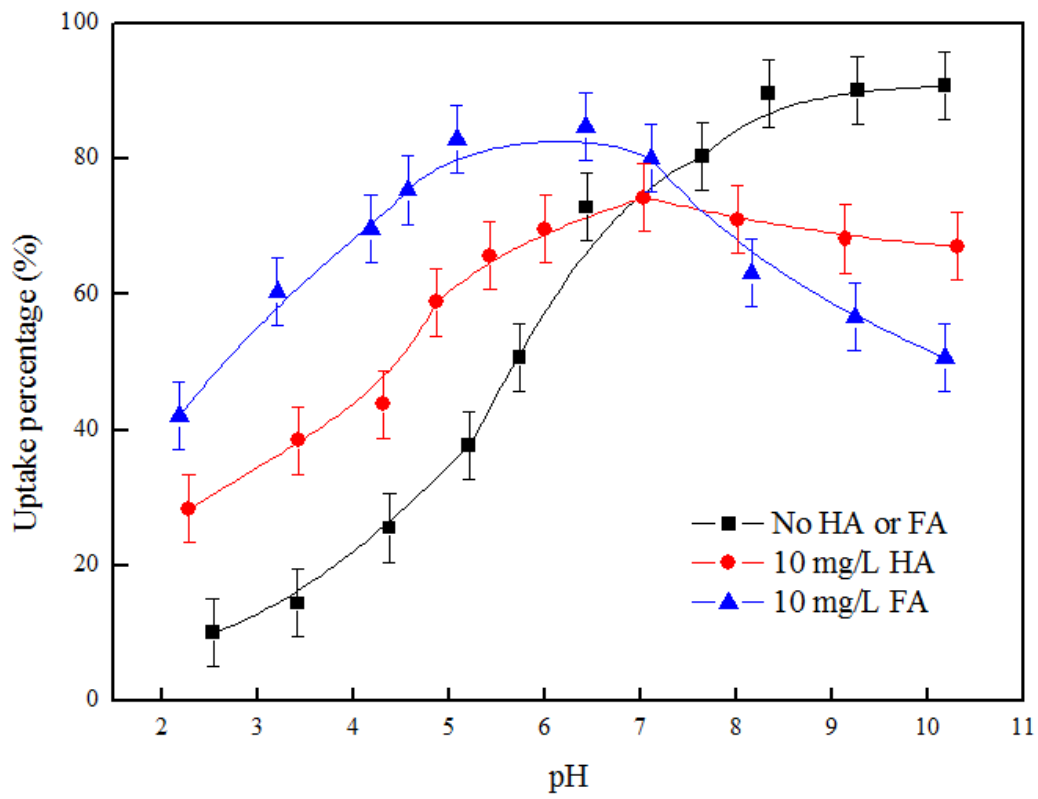

Fig. 5: The role of HA/FA in Co(II) uptake on GO, T $=293 \mathrm{~K}, \mathrm{C}_{\mathrm{Co}(\mathrm{II}) \text { initial }}=10 \mathrm{mg} / \mathrm{L}, \mathrm{m} / \mathrm{V}=0.1 \mathrm{~g} / \mathrm{L}, \mathrm{I}=0.1 \mathrm{~mol} / \mathrm{L} \mathrm{NaNO}_{3}$.

are conducted to simulate the uptake isotherms and to establish the relationship between the amount of $\mathrm{Co}$ (II) adsorbed on $\mathrm{GO}$ and the concentration of $\mathrm{Co}(\mathrm{II})$ remained in solution.

The Linear model (Sheng et al. 2012, Li et al. 2015) is as:

$$
q_{e}=A C_{e}+B
$$

where $\mathrm{C}_{\mathrm{e}}\left(\mathrm{mol} \cdot \mathrm{L}^{-1}\right)$ is the equilibrium concentration of $\mathrm{Co}(\mathrm{II})$ remained in the solution; $\mathrm{q}_{\mathrm{e}}\left(\mathrm{mol} \cdot \mathrm{g}^{-1}\right)$ is the amount of $\mathrm{Co}(\mathrm{II})$ adsorbed on per weight unit of GO after equilibrium.

The Langmuir model assumes that uptake occurs in a monolayer with all uptake sites identical and energetically equivalent (Sheng et al. 2012, Li et al. 2015). Its form can be described by the following equation:

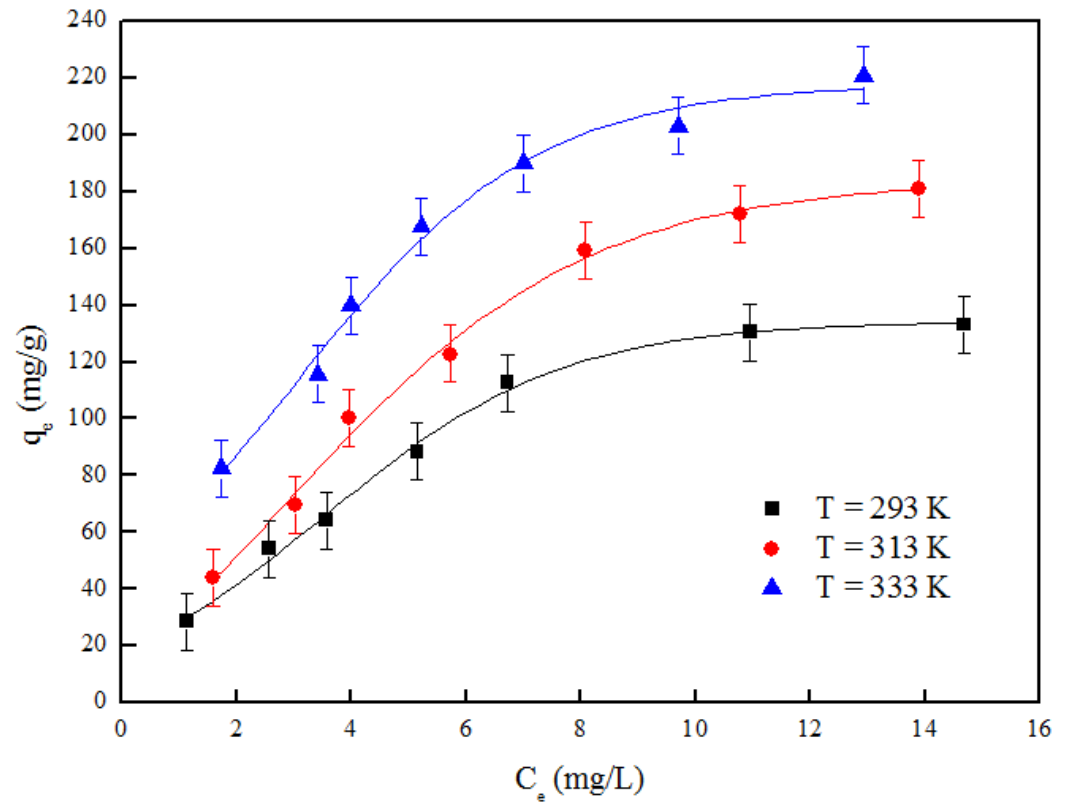

Fig. 6: Uptake isotherms of $\mathrm{Co}(\mathrm{II})$ uptake on GO at three different temperatures, $\mathrm{pH}=6.0 \pm 0.1, \mathrm{~m} / \mathrm{V}=0.1 \mathrm{~g} / \mathrm{L}, \mathrm{I}=0.1 \mathrm{~mol} / \mathrm{L} \mathrm{NaNO}$. 


$$
q_{e}=\frac{b q_{\max } C_{e}}{1+b C_{e}}
$$

which can be represented in the linear form:

$$
\frac{C_{e}}{q_{e}}=\frac{1}{b q_{\max }}+\frac{C_{e}}{q_{\max }}
$$

where $q_{\max }$ (the maximum uptake capacity, mol. $\mathrm{g}^{-1}$ ) is the amount of sorbate at complete monolayer coverage, and $b$ $\left(\mathrm{L} \cdot \mathrm{mol}^{-1}\right)$ is a constant that relates to the heat of uptake.

The Freundlich expression is an exponential equation with the assumption that as the sorbate concentration increases so too does the concentration of sorbate on the heterogeneous sorbent surface (Sheng et al. 2012). The equation is represented by the following equation:

$$
q_{e}=k_{F} C_{e}^{n}
$$

which can be expressed in linear form,

$$
\log q_{e}=\log k_{F}+n \log C_{e}
$$

where $\mathrm{k}_{\mathrm{F}}\left(\mathrm{mol}^{1-\mathrm{n}} \cdot \mathrm{L}^{\mathrm{n}} \cdot \mathrm{g}^{-1}\right)$ represents the uptake capacity when $\mathrm{Co}$ (II) equilibrium concentration equals 1 , and $\mathrm{n}$ represents the degree of dependence of uptake with equilibrium concentration.

The $\mathrm{D}-\mathrm{R}$ isotherm model is more general than the Langmuir isotherm since it does not have the restriction of surface properties or constant uptake potential (Sheng et al. 2012, Li et al. 2015). It has a general expression as follows:

$$
\begin{gathered}
q_{e}=q_{\text {max }} \exp \left(-\beta \varepsilon^{2}\right) \\
\ln q_{o}=\ln q_{\text {max }}-\beta \varepsilon^{2}
\end{gathered}
$$

where $\beta\left(\mathrm{mol}^{2} \cdot \mathrm{kJ}^{-2}\right)$ is the activity coefficient related to mean uptake energy, and $\varepsilon$ is the Polanyi potential, which is equal to:

$$
\varepsilon=R T \ln \left(1+\frac{1}{C_{e}}\right)
$$

where $\mathrm{R}\left(8.3145 \mathrm{~J} \cdot \mathrm{mol}^{-1} \cdot \mathrm{K}^{-1}\right)$ is ideal gas constant, and $\mathrm{T}$ $(\mathrm{K})$ is the absolute temperature in Kelvin.

$\mathrm{E}\left(\mathrm{kJ} \cdot \mathrm{mol}^{-1}\right)$ is defined as the free energy change, which requires to transfer $1 \mathrm{~mol}$ of $\mathrm{Co}$ (II) from solution to the GO surfaces. Its value can be calculated from the following equation:

$$
E=\frac{1}{\sqrt{2 \beta}}
$$

The experimental data of Co(II) uptake on GO are regressively simulated with the Linear, Langmuir, Freundlich, and D-R models, and the results are given in Fig. 7. The relative values calculated from the four models are listed in

\begin{tabular}{|c|c|c|c|c|c|}
\hline Linear model & A & & B & & $\mathrm{R}^{2}$ \\
\hline $\mathrm{T}=293 \mathrm{~K}$ & $6.5062 \times{ }^{1} 0-4$ & & 7.6581 & & 0.8583 \\
\hline $\mathrm{T}=313 \mathrm{~K}$ & $7.7276 \times 10^{-4}$ & & 11.2466 & & 0.8966 \\
\hline $\mathrm{T}=333 \mathrm{~K}$ & $1.4400 \times 10^{-4}$ & & 11.8902 & & 0.8711 \\
\hline Langmuir model & $\mathrm{q}_{\max }\left(\mathrm{mol} \cdot \mathrm{g}^{-1}\right)$ & & $\mathrm{b}\left(\mathrm{L} \cdot \mathrm{mol}^{-1}\right)$ & & $\mathrm{R}^{2}$ \\
\hline $\mathrm{T}=293 \mathrm{~K}$ & 0.0034 & & 8667.4731 & & 0.9709 \\
\hline $\mathrm{T}=313 \mathrm{~K}$ & 0.0054 & & 6164.5186 & & 0.9501 \\
\hline $\mathrm{T}=333 \mathrm{~K}$ & 0.0052 & & 12256.5000 & & 0.9862 \\
\hline Freundlich model & $K_{F}\left(m^{1-n}{ }^{1-n} \cdot L^{n} \cdot g^{-1}\right)$ & & $\mathrm{n}$ & & $\mathrm{R}^{2}$ \\
\hline $\mathrm{T}=293 \mathrm{~K}$ & 0.4806 & & 0.6263 & & 0.9629 \\
\hline $\mathrm{T}=313 \mathrm{~K}$ & 1.0403 & & 0.6808 & & 0.9630 \\
\hline $\mathrm{T}=333 \mathrm{~K}$ & 0.2914 & & 0.5067 & & 0.9558 \\
\hline D-R model & $\mathrm{q}_{\max }\left(\mathrm{mol} \cdot \mathrm{g}^{-1}\right)$ & $\beta\left(\mathrm{mol}^{2} \cdot \mathrm{kJ}^{-2}\right)$ & & $\mathrm{E}\left(\mathrm{kJ} \cdot \mathrm{mol}^{-1}\right)$ & $\mathrm{R}^{2}$ \\
\hline $\mathrm{T}=293 \mathrm{~K}$ & 0.0251 & $5.5520 \times{ }^{10}-3$ & & 9.4899 & 0.9744 \\
\hline $\mathrm{T}=313 \mathrm{~K}$ & 0.0437 & $5.3642 \times 10^{-3}$ & & 9.6546 & 0.9727 \\
\hline $\mathrm{T}=333 \mathrm{~K}$ & 0.0275 & $3.5286 \times 10^{-3}$ & & 11.9037 & 0.9654 \\
\hline
\end{tabular}
Table 2. As can be seen from Fig. 7 and Table 2, the Langmuir, Freundlich, and D-R isotherm equations simulate the experimental data of the uptake isotherms of $\mathrm{Co}$ (II) on GO more significantly than the Linear model, which is supported by the good correlation coefficients in Table 2. There is no apparent distinction between the fitting curves of the three

Table 2: The parameters for Linear, Langmuir, Freundlich, and D-R isotherms of Co(II) uptake on GO at different temperatures. 
models as can be seen from Fig. 7 and the $\mathrm{R}^{2}$ values of Langmuir, Freundlich, and D-R models (see Table 2). The result indicates that the whole surface of GO has identical uptake activity and therefore the adsorbed Co(II) ions do not interact or compete with each other, and they are adsorbed by forming an almost complete monolayer coverage of the GO particles, thus, the chemosorption is the principal uptake mechanism in uptake process.
The thermodynamic parameters $\left(\Delta \mathrm{G}^{0}, \Delta \mathrm{S}^{0}\right.$ and $\left.\Delta \mathrm{H}^{0}\right)$ for $\mathrm{Co}$ (II) uptake on $\mathrm{GO}$ can be determined from the temperature dependence. Free energy change $\left(\Delta G^{0}\right)$ is calculated from the relationship (Sheng et al. 2012, Li et al. 2015):

$$
\Delta G^{0}=-R T \ln K^{0}
$$

where $\mathrm{K}^{0}$ is the uptake equilibrium constant. Values of $\ln \mathrm{K}^{0}$ are obtained by plotting $\ln \mathrm{K}_{\mathrm{d}}$ versus $\mathrm{C}_{\mathrm{e}}$ for uptake of $\mathrm{Co}$ (II)
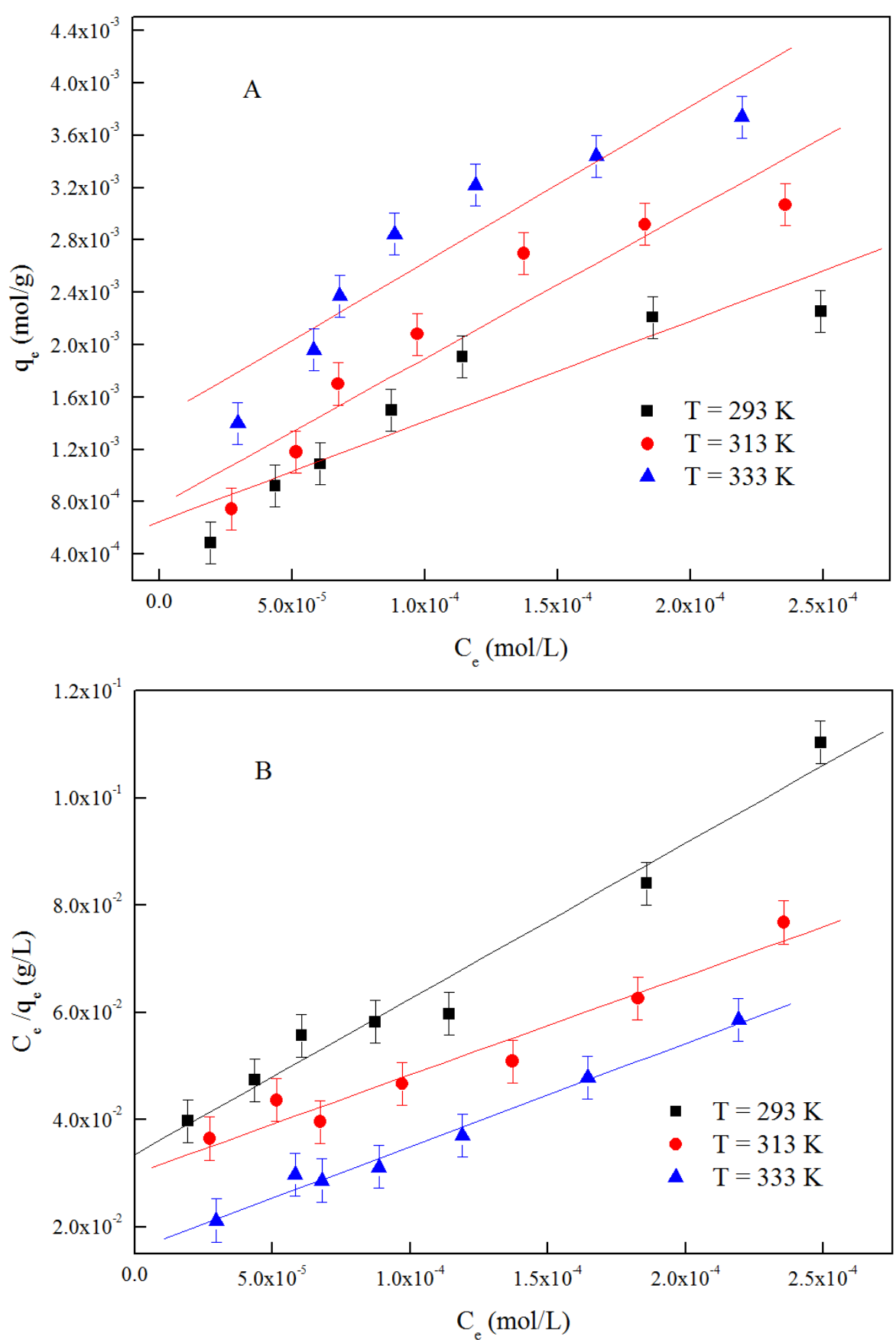

Fig. Cont.... 

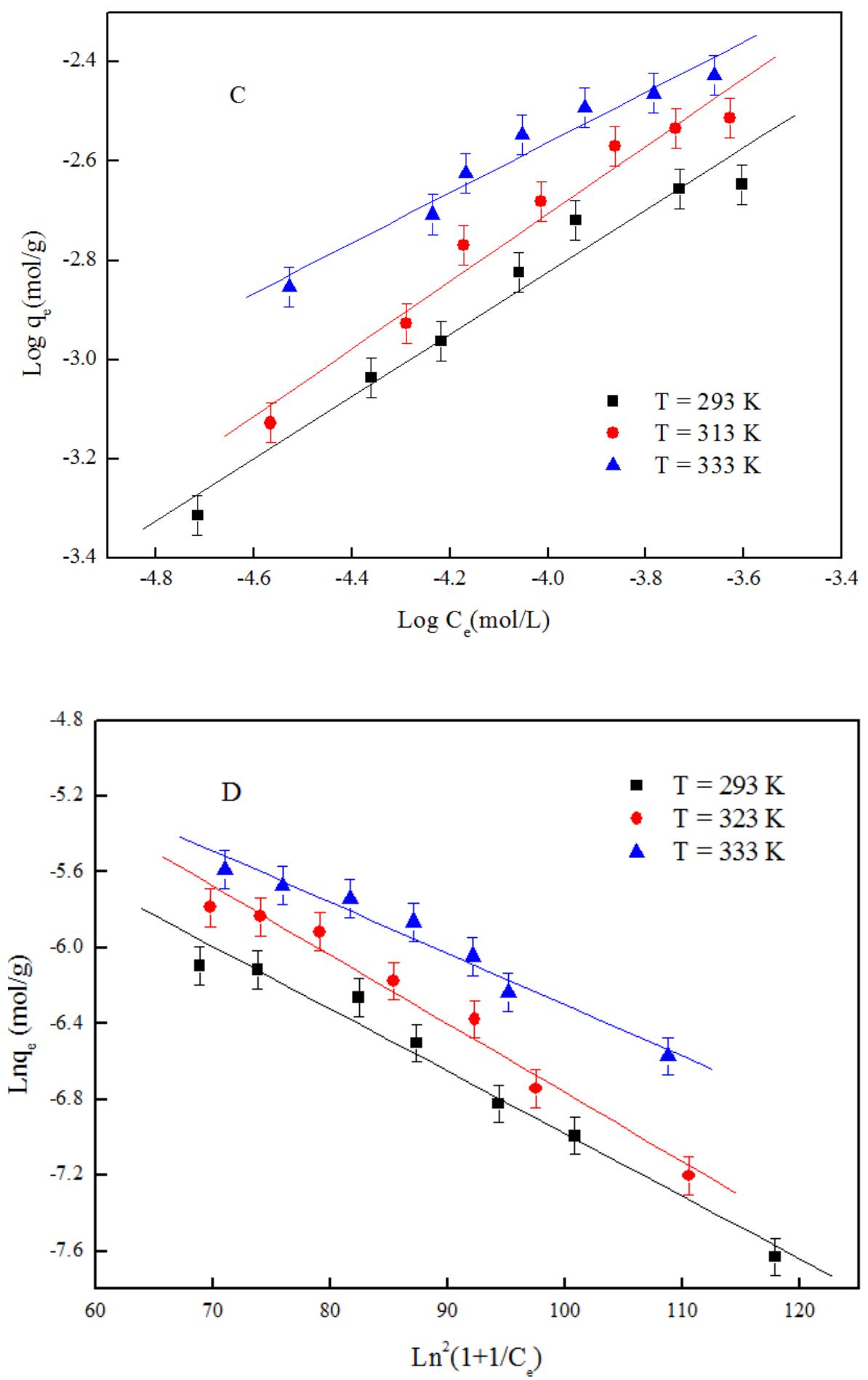

Fig. 7: Fitting results of (A) Linear, (B) Langmuir, (C) Freundlich and (D) D-R adsorption isotherms of Co(II) uptake on GO at three different temperatures, $\mathrm{pH}=6.0 \pm 0.1, \mathrm{~m} / \mathrm{V}=0.1 \mathrm{~g} / \mathrm{L}, \mathrm{I}=0.1 \mathrm{~mol} / \mathrm{L} \mathrm{NaNO}_{3}$. 
on $\mathrm{GO}$ (Fig. 8A) and extrapolating $\mathrm{C}_{\mathrm{e}}$ to zero are 10.14 ( $\mathrm{T}=$ $293 \mathrm{~K}), 10.31(\mathrm{~T}=313 \mathrm{~K})$ and $10.82(\mathrm{~T}=333 \mathrm{~K})$, respectively. Standard entropy change $\left(\Delta S^{0}\right)$ evaluated from the slope which linear plot of $\Delta \mathrm{G}^{0}$ versus $\mathrm{T}$ is achieved according to the equation (Fig. 8B):

$$
\left(\frac{\partial \Delta G^{0}}{\partial T}\right)_{p}=-\Delta S^{0}
$$

The average standard enthalpy change $\left(\Delta \mathrm{H}^{0}\right)$ is then calculated from the expression:

$$
\Delta H^{0}=\Delta G^{0}+T \Delta S^{0}
$$

The values obtained from Eqs. (14) to (15) are tabulated in Table 3. A positive value of the $\Delta \mathrm{H}^{0}$ suggest that the uptake of $\mathrm{Co}(\mathrm{II})$ on $\mathrm{GO}$ is endothermic. One possible explanation for this positive $\Delta \mathrm{H}^{0}$ is that $\mathrm{Co}(\mathrm{II})$ is solved well in water, and the hydration sheath of $\mathrm{Co}$ (II) has to be destroyed before its uptake on GO. This dehydration process needs energy, and it is favored at high temperatures. The Gibbs free energy change $\left(\Delta G^{0}\right)$ is negative as expected for a spontaneous process under the conditions applied. The value of $\Delta \mathrm{G}^{0}$ becomes more negative with the increase of temperature, which indicates that the reaction is more favorable at higher temperatures. At high temperatures, cations are readily desolvated and hence its sorption becomes more favorable. The positive value of entropy change $\left(\Delta S^{0}\right)$ implies some structural changes in
$\mathrm{Co}$ (II) and GO during the uptake process, which leads to an increase in the disorderliness of the GO-solution interfacial system during the uptake of $\mathrm{Co}(\mathrm{II})$ on GO. The thermodynamic analysis derived from temperature-dependent uptake isotherms suggests that the uptake process of $\mathrm{Co}$ (II) on GO is spontaneous and endothermic.

\section{Regeneration and Reuse}

For the environmental sustainability of GO, it is essential to describe regeneration aspects of the process to improve its cost-effectiveness by recycling the GO for reuse in multiple cycles. Fig. 9 displays that the uptake of $\mathrm{Co}$ (II) on the GO with three different concentrations (i.e., $0.05,0.1$, and 0.2 $\mathrm{g} / \mathrm{L})$ after 6 times of uptake and desorption process at $\mathrm{pH}=$ 6.0 and $\mathrm{T}=293 \mathrm{~K}$. As shown in Fig. 9, after six cycles, the uptake efficiency decreased from $53 \%$ to $49 \%(\mathrm{GO}=0.05$ $\left.\mathrm{g} \cdot \mathrm{L}^{-1}\right), 69 \%$ to $64 \%\left(\mathrm{GO}=0.1 \mathrm{~g} \cdot \mathrm{L}^{-1}\right), 74 \%$ to $69 \%(\mathrm{GO}=0.2$ $\left.\mathrm{g} \cdot \mathrm{L}^{-1}\right)$, respectively. The results suggested that the GO after 6 times usage could be efficiently regenerated and reused

Table 3: Values of thermodynamic parameters for Co(II) uptake on GO.

\begin{tabular}{|llll|}
\hline $\mathrm{T}(\mathrm{K})$ & $\Delta \mathrm{G}^{0}\left(\mathrm{~kJ} \cdot \mathrm{mol}^{-1}\right)$ & $\Delta \mathrm{S}^{0}\left(\mathrm{~J} \cdot \mathrm{mol}^{-1} \cdot \mathrm{K}^{-1}\right)$ & $\Delta \mathrm{H}^{0}\left(\mathrm{~kJ} \cdot \mathrm{mol}^{-1}\right)$ \\
\hline 293 & -24.7096 & 130.9828 & 13.6683 \\
313 & -26.8193 & & 14.1783 \\
333 & -29.9489 & & 13.6684 \\
\hline
\end{tabular}

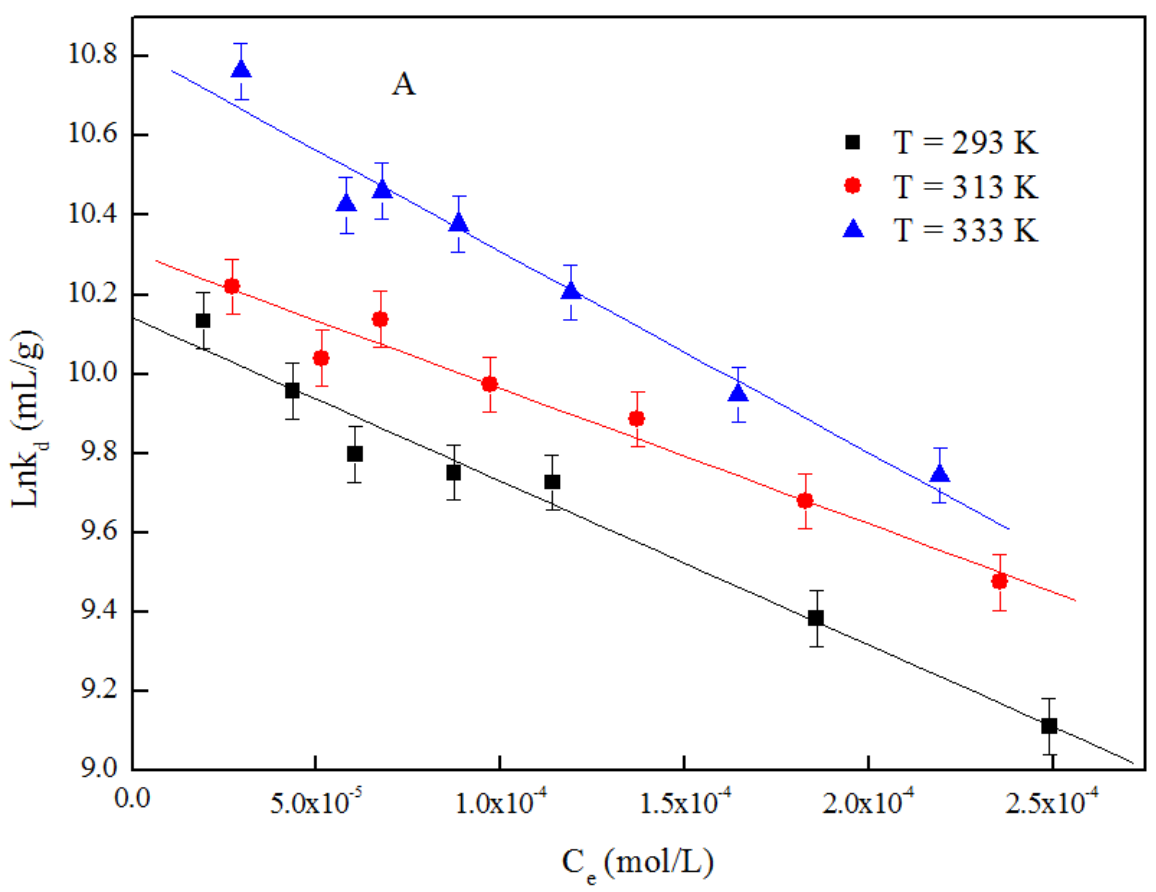

Fig. Cont.... 


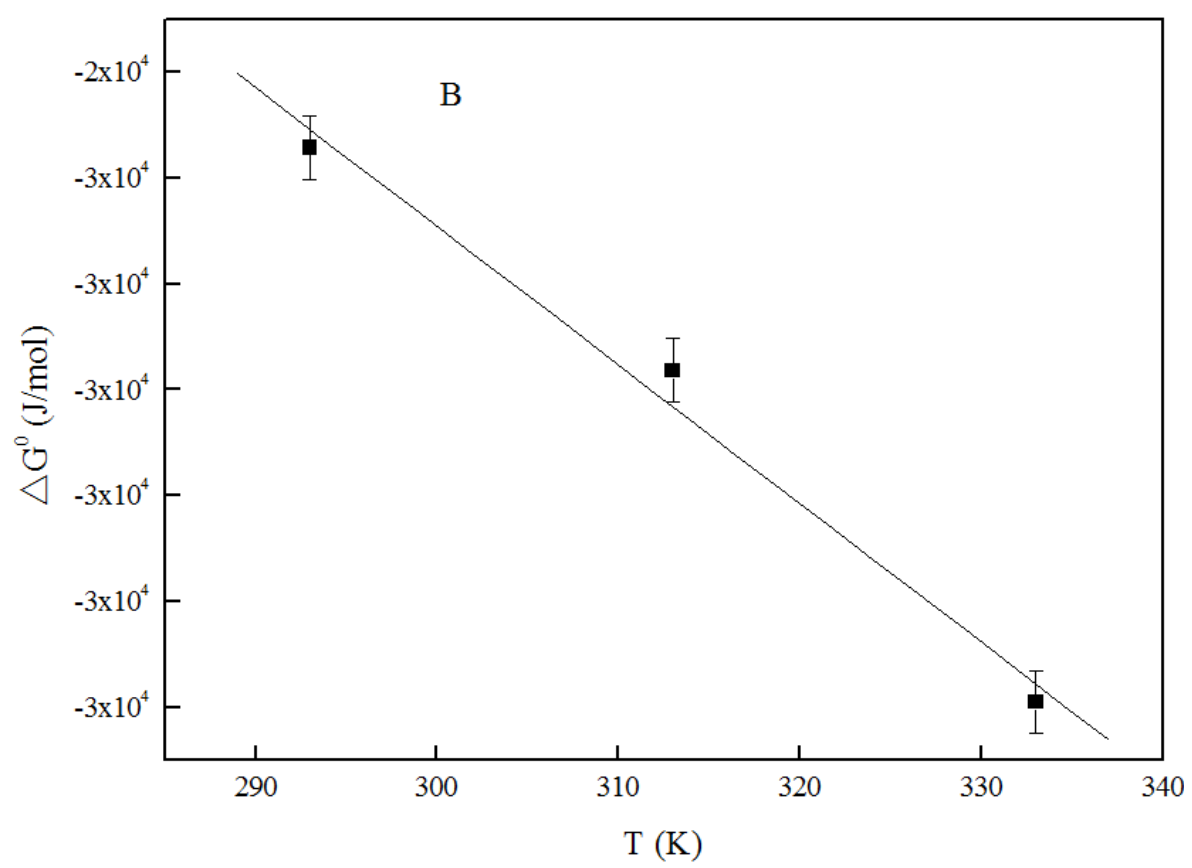

Fig. 8: The linear plot of (A) $\mathrm{LnK}_{d}$ versus $\mathrm{C}_{\mathrm{e}}$ at three different temperatures and (B) $\Delta \mathrm{G}^{0}$ versus $\mathrm{T}$ for Co(II) uptake on GO, $\mathrm{pH}=6.0 \pm 0.1, \mathrm{~m} / \mathrm{V}=0.1 \mathrm{~g} / \mathrm{L}$.

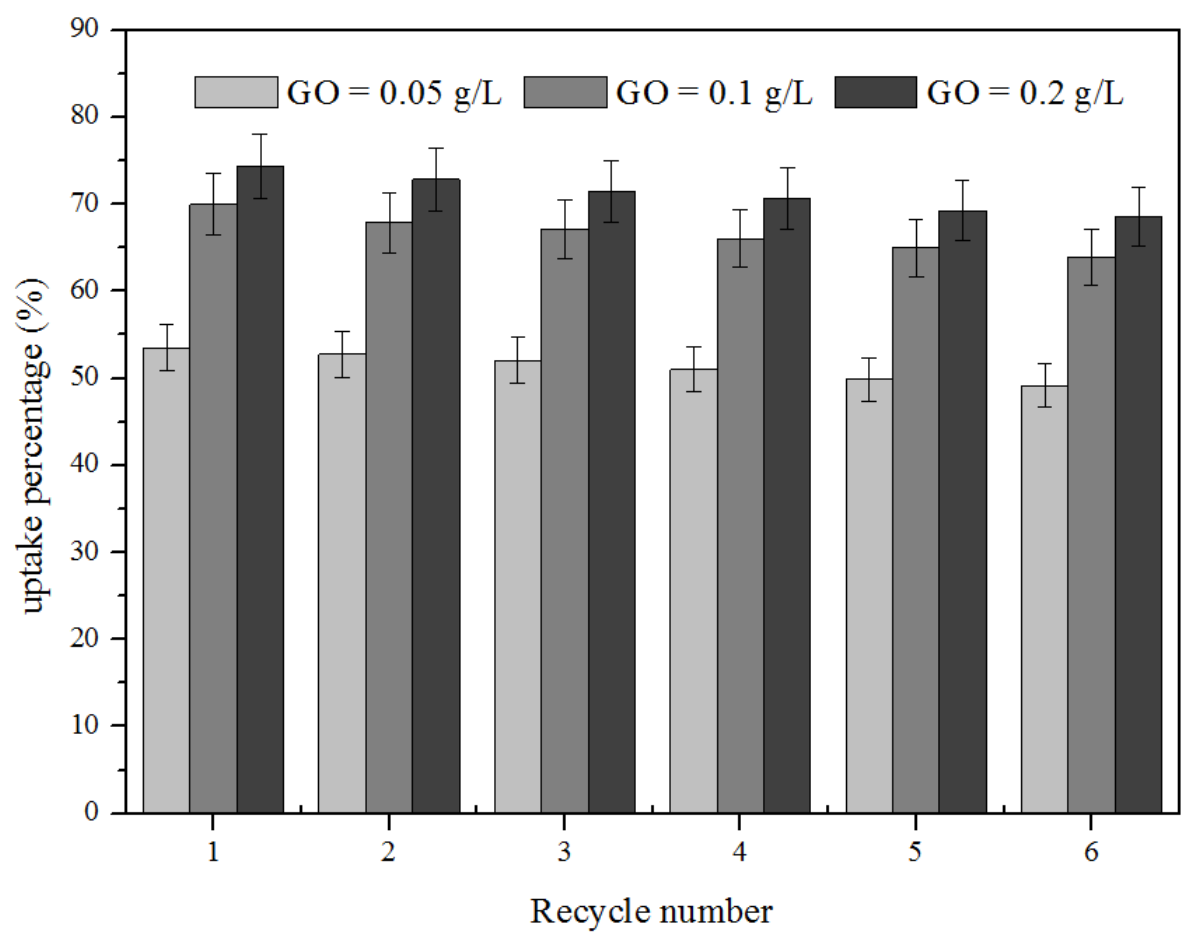

Fig. 9: Recycling for Co(II) uptake on GO of three different concentrations, $\mathrm{T}=293 \mathrm{~K}, \mathrm{pH}=6.0 \pm 0.1, \mathrm{C}_{\mathrm{Co}(\mathrm{II}) \text { initial }}=10 \mathrm{mg} / \mathrm{L}, \mathrm{I}=0.1 \mathrm{~mol} / \mathrm{L} \mathrm{NaNO}$. 
with a slight decrease in uptake efficiency, which may enhance the economy of the adsorption process. The excellent repeatability of GO indicated that GO is promising for the natural attenuation of $\mathrm{Co}(\mathrm{II})$ and related metal ions from an aqueous solution.

\section{CONCLUSIONS}

In this study, the batch technique was adopted to investigate the uptake of $\mathrm{Co}$ (II) on $\mathrm{GO}$ as a function of various water chemistries such as contact time, $\mathrm{pH}$, ionic strength, and temperature under ambient conditions. From the results of $\mathrm{Co}$ (II) uptake on GO under our experimental conditions, the following conclusions can be obtained:

(1) Kinetic studies suggest that $\mathrm{Co}$ (II) uptake on GO could be described more favorably by the pseudo-second-order kinetic model.

(2) The uptake of Co(II) on GO is strongly dependent on $\mathrm{pH}$ values. The uptake increases with $\mathrm{pH}$ increasing at $\mathrm{pH}<8.0$, and then the uptake maintains a high level at $\mathrm{pH}>8.0$.

(3) The uptake of $\mathrm{Co}$ (II) on GO is independent of ionic strength in the wide $\mathrm{pH}$ range and thus inner-sphere surface complexation is the main mechanism responsible for the uptake of $\mathrm{Co}$ (II) on GO.

(4) The uptake of Co(II) is influenced by HA/FA significantly, and the effect of HA/FA on Co(II) uptake is dependent on $\mathrm{pH}$ values. The presence of HA/FA enhances the uptake of $\mathrm{Ni}$ (II) on $\mathrm{GO}$ at low $\mathrm{pH}$, while reduces $\mathrm{Co}(\mathrm{II})$ uptake on $\mathrm{GO}$ at high $\mathrm{pH}$.

(5) The Langmuir, Freundlich, and D-R isotherm equations simulate the experimental data of the uptake isotherms of $\mathrm{Co}$ (II) on GO more significantly than the Linear model, and there is no apparent distinction among the fitting curves of the three models of Langmuir, Freundlich, and D-R models.

(6) The thermodynamic analysis from the temperature-dependent uptake isotherms suggests that the uptake of $\mathrm{Co}(\mathrm{II})$ on $\mathrm{GO}$ is spontaneous and endothermic.

\section{ACKNOWLEDGEMENTS}

This work was supported by the Science Foundation of the Ministry of Education of China (201802227004).

\section{REFERENCES}

Almasian, A., Giyahi, M. H., Dehdast, S.A. and Maleknia, L. 2018 Removal of heavy metal ions by modified pan/pani-nylon core-shell nanofibers membrane: filtration performance, antifouling, and regeneration behavior. Chem. Eng. J., 351(1): 1166-1178.
Arancibia-Miranda, N., Baltazar, S.E., García, A., Munoz-Lira, D., Sepúlveda, P., Rubio, M.A. and Altbir, D. 2016. Nanoscale zero valent iron supported by zeolite and montmorillonite: Template effect of the removal of lead ion from an aqueous solution. J. Hazard. Mater., 301: 371-380.

Bhatnagar, A., Minocha, A.K. and Sillanpää, M. 2010. Adsorptive removal of cobalt from aqueous solution by utilizing lemon peel as biosorbent. Biochem. Eng. J., 48(2): 181-186.

Bradder, P., Ling, S., Wang, S. and Liu, S. 2011. Dye adsorption on layered graphite oxide. J. Chem. Eng. Data., 56(1): 138-141.

Chen, L., Huang, Y., Huang, L., Liu, B., Wang, G. and Yu. S. 2011. Characterization of $\mathrm{Co}$ (II) removal from aqueous solution using bentonite/iron oxide magnetic composites. J. Radioanal. Nucl. Chem., 290(3): 675-684.

Chen, Q., Yao, Y., Li, X., Lu, J., Zhou, J. and Huang, Z. 2018. Comparison of heavy metal removals from aqueous solutions by chemical precipitation and characteristics of precipitates. J. Water Process Eng., 26: 289-300.

Cheng, W., Ding, C., Sun, Y. and Wang, X. 2015. Fabrication of fungus/ attapulgite composites and their removal of U(VI) from aqueous solution. Chem. Eng. J., 269: 1-8.

Deng, J., Zhang, X., Zeng, G., Gong, J., Niu, Q. and Liang, J. 2013. Simultaneous removal of $\mathrm{Cd}(\mathrm{II})$ and ionic dyes from aqueous solution using magnetic graphene oxide nanocomposite as an adsorbent. Chem. Eng. J., 226(8): 189-200.

Ding, C., Cheng, W., Sun, Y. and Wang, X. 2015. Effect of Bacillus subtilis on the reduction of U(VI) by nano-Fe. Geochim. Cosmochim. Acta., 165: 86-107.

Gao, W., Majumder, M., Alemany, L., Narayanan, T., Ibarra, M., Pradhan, B. and Ajayan, P. 2011. Engineered graphite oxide materials for application in water purification. ACS. Appl. Mater. Interfaces, 3(6): $1821-1826$

Hayes, K. and Leckie, J. 1987. Modeling ionic strength effects on cation adsorption at hydrous oxide/solution interfaces. J. Colloid. Interf. Sci. ,115(2): 564-572.

Hu, B., Cheng, W., Zhang, H. and Sheng, G. 2010. Sorption of radionickel to goethite: effect of water quality parameters and temperature. J. Radioanal. Nucl. Ch. 285(2): 389-398.

Huang, J., Liu, Y. and Wang, X. 2008. Selective sorption of tannin from flavonoids by organically modified attapulgite clay. J. Hazard. Mater., 160(2-3): 382-387.

Jin, Z., Sheng, J. and Sun, Y. 2014. Characterization of radioactive cobalt on graphene oxide by macroscopic and spectroscopic techniques. J. Radioanal. Nucl. Chem., 299(3): 1979-1986.

Jin, Z., Wang, X., Sun, Y., Ai, Y. and Wang, X. 2015. Adsorption of 4-n-nonylphenol and bisphenol-A on magnetic reduced graphene oxides: A combined experimental and theoretical studies. Environ. Sci. Technol., 49(15): 9168-9175.

Komatsu, Y. 2010. Research for ion-exchange separation of metal ions. J. Ion. Exch., 10(1): 8-14.

Li, J., Chen, S., Sheng, G., Hu, J., Tan, X. and Wang, X. 2011. Effect of surfactants on $\mathrm{Pb}$ (II) adsorption from aqueous solutions using oxidized multiwall carbon nanotubes. Chem. Eng. J., 166(2): 551-558.

Li, X., Fang, Y. and Tang, X. 2014. Using graphene oxide as a superior adsorbent for the highly efficient immobilization of $\mathrm{Cu}$ (II) from aqueous solution. J. Mol. Liq., 199: 237-243.

Li, X., Yu, M., Lv, Q. and Tan, Y. 2015. Sequestration of Ni(II) onto graphene oxide from synthetic wastewater as affected by coexisting constituents. Desalin. Water. Treat. DOI:10.1080/19443994.2015.1110841.

Luo, J., Zhao, D., Wang, L., Asiri, A.M. and Alamry, K.A., 2019. Simultaneous Removal of $\mathrm{Cu}$ (II) and 1-Naphthol in Wastewater by Magnetic Nanoparticle-Graphene Oxide Composites. Nat. Environ. Pollut. Technol., 18(3): 777-787 
Ma, M., Gao, H., Sun, Y. and Huang, M. 2015. The adsorption and desorption of $\mathrm{Ni}(\mathrm{II})$ on Al substituted goethite. J. Mol. Liq., 201: 30-35.

Mobasherpour, I., Salahi, E. and Ebrahimi, M. 2014. Thermodynamics and kinetics of adsorption of $\mathrm{Cu}(\mathrm{II})$ from aqueous solutions onto multi-walled carbon nanotubes. J. Saudi. Chem. Soc., 18(6): 792-801.

Mou, J., Li, C., Wang, G. and Shi, W. 2012. Complexation and sorption studies of $\mathrm{Co}$ (II) with $\gamma$-alumina-bound fulvic acid: effect of $\mathrm{pH}$, ionic strength, fulvic acid, and alumina concentration. J. Radioanal. Nucl. Chem., 292(3): 1099-1104.

Pei, Z., Li, L., Sun, L., Zhang, S., Shan, X., Yang, S. and Wen, B. 2013. Adsorption characteristics of 1,2,4-trichlorobenzene, 2,4,6-trichlorophenol, 2-naphthol, and naphthalene on graphene and graphene oxide. Carbon, 51(1): 156-163.

Ramesha, G., Vijaya, Kumara. A., Muralidhara, H. and Sampath, S. 2011. Graphene and graphene oxide as effective adsorbents toward anionic and cationic dyes. J. Colloid. Interf. Sci., 361(1): 270-277.

Sheng, G., Dong, H. and Li, Y. 2012. Characterization of diatomite and its application for the retention of radiocobalt: role of environmental parameters. J. Environ. Radioact., 113: 108-115.

Sheng, G., Yang, Q., Peng, F., Li, H., Gao, X. and Huang, Y. 2014a. Determination of colloidal pyrolusite, $\mathrm{Eu}(\mathrm{III})$ and humic substance interaction: A combined batch and EXAFS approach. Chem. Eng. J., 245(4): 10-16.

Sheng, G., Ye, L., Li, Y., Dong, H., Li, H., Gao, X. and Huang, Y. 2014b. EXAFS study of the interfacial interaction of nickel(II) on titanate nanotubes: Role of contact time, $\mathrm{pH}$, and humic substances. Chem. Eng. J., 248(1): 71-78.

Sheng, G., Alsaedi, A., Shammakh, W., Monaquel, S., Sheng, J., Wang, X., Li, H. and Huang, Y. 2016. Enhanced sequestration of selenite in water by nanoscale zero-valent iron immobilization on carbon nanotubes by a combined batch, XPS, and XAFS investigation. Carbon, 99: 123-130.

Shibi, I.G. and Anirudhan, T.S. 2005. Adsorption of Co(II) by a carboxylate- functionalized polyacrylamide grafted lignocellulosic. Chemosphere, 58(8): 1117-1126.

Sun, Y., Yang, S., Chen, Y., Ding, C., Cheng, W. and Wang, X. 2015. Adsorption and desorption of $\mathrm{U}(\mathrm{VI})$ on functionalized graphene oxides: A combined experimental and theoretical study. Environ. Sci. Technol., 49(7): 4255-4262.

Tan, X., Fan, Q., Wang, X. and Grambow, B. 2009. Eu(III) sorption to $\mathrm{TiO}_{2}$ (anatase and rutile): batch, XPS, and EXAFS studies. Environ. Sci. Technol., 43(9): 3115-3121.

Wang, J., Chen, Z. and Chen, B. 2014. Adsorption of polycyclic aromatic hydrocarbons by graphene and graphene oxide nanosheets. Environ. Sci. Technol., 48(9): 4817-4825.

Yang, S., Hu, J., Chen, C., Shao, D. and Wang, X. 2011. Mutual effects of $\mathrm{Pb}$ (II) and humic acid adsorptions on multiwalled carbon nanotubes/ polyacrylamide composites from aqueous solutions. Environ. Sci. Technol., 45(8): 3621-3627.

Zhao, G., Li, J., Ren, X., Chen, C. and Wang, X. 2011. Few-layered graphene oxide nanosheets as superior sorbents for heavy metal ion pollution management. Environ. Sci. Technol., 45(24): 10454-10462.

Zhang, S., Guo, Z., Xu, J., Niu, H., Chen, Z. and Xu, J. 2011. Effect of environmental conditions on the sorption of radiocobalt from aqueous solution to a treated eggshell as biosorbent. J. Radioanal. Nucl. Chem., 288(1): 121-130.

Zhang, X., Wang, Y. and Yang, S. 2014. Simultaneous removal of Co(II) and 1-naphthol by core-shell structured $\mathrm{Fe}_{3} \mathrm{O}_{4} @$ cyclodextrin magnetic nanoparticles. Carbohydrate. Polymers, 114: 521-529. 